\title{
Influence of 3D Printing on Industrial Design
}

\author{
Chong $\operatorname{Tan}^{1, \mathrm{a}^{*}}$ and Chengcheng $\mathrm{Li}^{2, \mathrm{~b}}$ \\ ${ }^{1}$ Key Laboratory of Metallurgical Equipment and Control Technology, Ministry of Education, \\ Wuhan University of Science and Technology, Wuhan 430081, China; \\ ${ }^{2}$ Hubei Key Laboratory of Mechanical Transmission and Manufacturing Engineering, \\ Wuhan University of Science and Technology, Wuhan 430081, China; \\ atc18983100080@163.com, ${ }^{b} 1271693864 @ q q . c o m$
}

Keywords: 3D printing technology; Industrial design; Intelligence manufacturing; Opportunities and challenges

\begin{abstract}
D printing is a new type of mainstream processing technology in the field of industrial design. Compared with traditional manufacturing technology, 3D printing can manufacture more complex products with low cost, high efficiency and simple operation. It use the computer software design and modeling of three-dimensional digital materials with the material printer to promote the manufacture of products. Industrial design is one of the most important applications of 3D printing technology, so the author mainly studies and analysis the opportunities brought by 3D printing technology for industrial design and how to actively face the challenge. Through the research, we found that 3D printing technology has brought good prospects for industrial design, which not only accelerate the development of industrial design, but also make the manufacturing of products to meet the needs of more users.
\end{abstract}

\section{Introduction}

The 21st century is an era of rapid development of science and technology. Three-dimensional printing is one of the important technologies [1]. As 3D printing has the great advantages of low cost and high efficiency, it has become a very popular technology in all walks of life in recent years. According to China Industrial Information Network "2017-2021 China Industry 4.0 Industry Research and Future Forecast Report" the total market size of China's 3D printing industry will reach 2.57 billion dollars this year, and the average annual compound of the next five years (2017-2021) the increase rate is about $41.36 \%$. It is estimated that the market size of 3D printing in China will reach 1 billion dollars by 2021 [2].

In the face of the rapid development of 3D printing technology, some experts said that 3D printing technology will become a sunrise industry with a promising prospect in the future and gradually integrate into people's life. With the gradual maturity and popularity of 3D printing technology, its existence will greatly change the traditional product design and product manufacturing process. This paper first combines the principles and characteristics of 3D printers, describes the type of $3 \mathrm{D}$ printing in the field of industrial design and application status quo. Secondly, according to the future development trend of 3D printing technology, a series of opportunities and challenges brought by the three-dimensional printing technology to industrial design are studied and analyzed. The purpose of the study is to enable enterprises and industrial designers to firmly grasp the opportunities brought by 3D printing technology to industrial design, and to promote the sustained and healthy development of industrial design.

\section{D Printing Technology}

The principle of 3D printing technology. 3D printing is also called rapid prototyping technology, materials manufacturing technology and incremental manufacturing technology, it is through the computer three-dimensional design software for new product model design, and then through the three-dimensional design software to design a good model is decomposed into many layers of flat 
dicing. Finally, a series of printable raw materials are stacked and stacked layer by layer by a numerical control forming system to produce the physical product technology [3]. As shown in Fig. $13 \mathrm{D}$ printing workflow diagram, 3D printing is divided into design modeling and printing two stages:

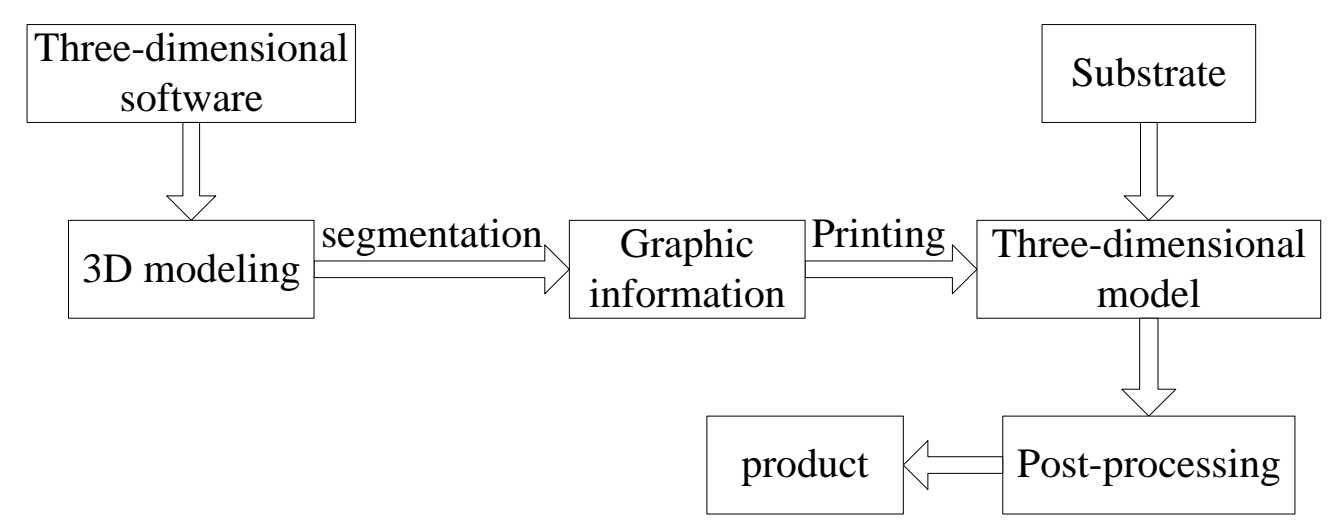

Figure 1. 3D printing workflow

(1) 3D design modeling stage. Corporate design department can use some of the three-dimensional cartographic software (such as ATUOCAD, SOLIDWORKS, UG, etc.) for product model design and production. As shown in Fig 2 is use of the SOLIDWORKS established screwdriver 3D model. You can also use some professional 3D scanner or some DIY scanning device to get the 3D data of the object to be printed, and finally generate the 3D model in digital mode [4]. Of course, designers can also use the 3D models others have already done.

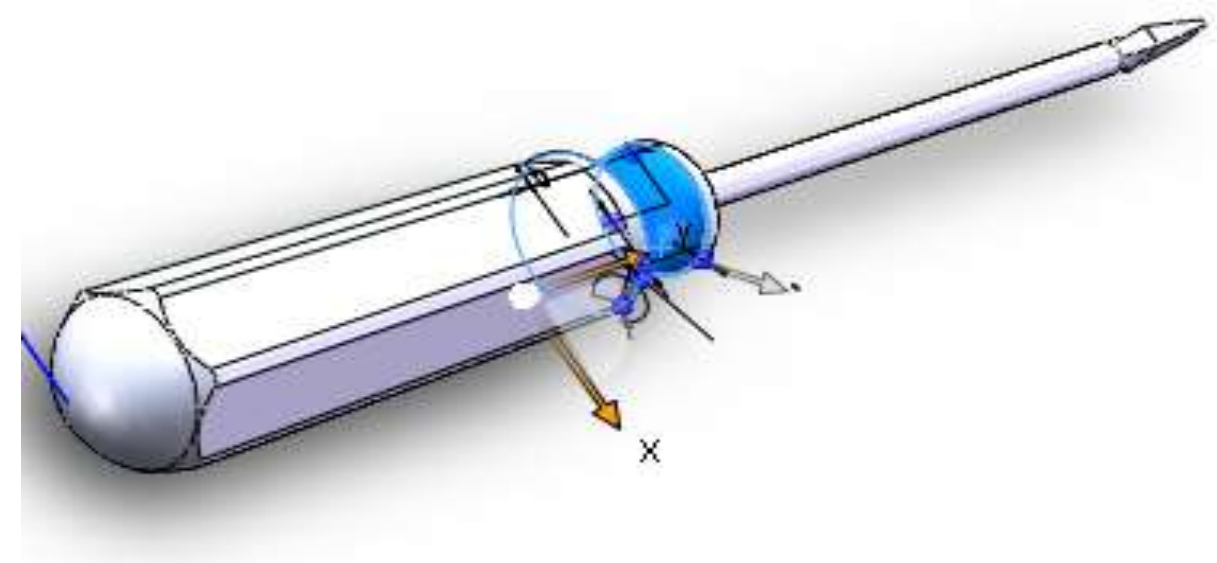

Figure 2. Flat screwdriver 3D model

(2) 3D printing stage. The first is the $3 \mathrm{D}$ printer to read the product information related to the product model and cut layer by layer to build, and secondly print it layer by layer, and finally all layers glued together in many ways to create a solid model of the product. First-time manufacturing products are usually rough, or there are many glitches [5], then the need for further processing later. After the post-processing (such as polishing, etc.) before it can put into production.

3D printing technology features. (1) The advent of 3D printing has led to a great revolution in manufacturing. The traditional product design and manufacturing rely mainly on production technology to achieve, and the emergence of 3D printing technology will subvert the concept of production, making industrial design will not consider the process can be achieved.

(2) As companies use 3D printing to produce new products, some of the problems associated 
with machining and tooling are avoided [6]. It can generate objects of any shape directly from model data designed by computer 3D software to realize the integration of design and manufacture.

(3) The diversity of printed materials. At present, 3D printing system can print hundreds kinds of raw materials and cover many fields such as aerospace, construction, medical care, education, jewelry, toys and the like.

(4) 3D printing has made it possible for people to buy these printers in some electronics stores, and factories are also going direct sales. Scientists say the use of 3D printers is still limited, but people will be able to print more usable items through 3D printers in the future.

\section{Application Status of 3D Printing Technology in Industrial Design}

$3 \mathrm{D}$ printing has changed the way people live and commodities production to a certain extent. 3D printing technology has been widely used in many industrial design fields such as product prototype, mold manufacturing, jewelry, electronic consumer, furniture and toys.

The production of tools for industrial design. Industrial design is a cross product of multi discipline, technology and aesthetic concept, and it is a creative activity [7]. Instead of spending a lot of time designing and manufacturing, these tools can be done with 3D printers, and companies no longer need to spend more time and money buying and installing them, thus effectively improving their product assembly and manufacturing processes. Meet the design requirements and consumer needs.

Personalized models and functional prototypes. As we all know, in the industrial design of the production process requires a wide range of parts, models, and the use of 3D printing technology can be quickly and efficiently completed.

In addition, the application of 3D printing in industrial design is also reflected in the following aspects, as shown in Table 1, the main application of 3D printing in the field of industrial design:

Table $13 \mathrm{D}$ printing in the field of industrial design applications

\begin{tabular}{cc}
\hline $\begin{array}{c}\text { Industrial } \\
\text { Design }\end{array}$ & Application content \\
\hline $\begin{array}{c}\text { Industrial } \\
\text { Products }\end{array}$ & $\begin{array}{c}\text { 3D printing can be used directly to produce molds, components } \\
\text { and products. It can print complex shapes with high efficiency, } \\
\text { low cost, high precision and a small number of custom parts. }\end{array}$ \\
\hline $\begin{array}{c}\text { Product model design, prototype design, product quality } \\
\text { Product design } \\
\text { instion. For example, Microsoft has created a 3D printer } \\
\text { shop to print prototypes for create better products. }\end{array}$ \\
\hline $\begin{array}{c}\text { Ergonomics } \\
\text { research }\end{array}$ & $\begin{array}{c}\text { By 3D scanning of the human body, an accurate human 3D } \\
\text { model can be printed and suitable for teaching research, which } \\
\text { can promote the rapid development of medical and health work. }\end{array}$ \\
\hline $\begin{array}{c}\text { The design and manufacture of toys, jewelry, apparel and DIY } \\
\text { goods }\end{array}$ & $\begin{array}{r}\text { Modern electronic products commonly used, such as } \\
\text { which can be printed using 3D printers. }\end{array}$ \\
\hline $\begin{array}{c}\text { Electronic } \\
\text { product }\end{array}$ & $\begin{array}{r}\text { headphones, smart kits, phone case and so on. You are free to } \\
\text { print your favorite items. }\end{array}$ \\
\hline
\end{tabular}

\section{D Printing Opportunities for Industrial Design}

The future is an era of high-tech integration of intelligence, big data, cloud and artificial intelligence. Technological advances will bring about major changes in social production. As an important technology, 3D printing has brought a series of brand-new opportunities to industrial design [8].

Design inspiration is more active. In the traditional manufacturing process, due to the structural 
and technological limitations, many industrial designers' inspiration and creativity only stay in the mind and cannot be realized in actual production. However, the emergence of 3D printing technology, the design inspiration for industrial designers to provide a great convenience. Only requires designers to master the computer control language, proficient use of 3D modeling software, you can fully express their ideas, and ultimately by the 3D printer to the model in his mind perfect reality show, without understand the traditional hundreds of production process requirements and processes [9].

Customization is easier. Traditional product design of mass production, mainly to meet the diverse needs of users to adapt to a limited style and mode, and greatly overlooked the differences of users. With the abundance of products, the needs of consumers have also become larger and larger. The advent of 3D printing has embodies personalized and intelligent features that make personalized design and manufacture possible. Users can use simple methods and cheaper costs to use 3D printers to develop their own personalized products.

Product development cycle shorter. Time to market of new products is often very concerned about consumers, but also an important factor for businesses to get more profits [10]. The key to whether a company can achieve high profits lies in whether new products can be put on the market in time. The only way to shorten lead time in product lifecycle development is to reduce the transition time from design drawings to product models. Currently, with the same amount of material used to make a product, 3D printers are three times more productive than traditional methods and can independently optimize the product design process.

Product development risk is lower. Manufacturing industries often prepare a large amount of inventory to meet the needs of users. However, in practice, there often occur too many overstocked products and the oversupply phenomenon, which eventually leads to the loss of the enterprises [11]. The emergence of 3D printers, only your design model has been on your computer, the product can be produced at any time by 3D printing out, grasp the production volume according to the order. Therefore, we can achieve zero inventory, the company can in accordance with the production order to production in time. This is a very good option for newly formed companies and for corporate investors because of the new product development costs and risks are reduced.

\section{The Challenge of 3D Printing to Industrial Design}

The 3D printing technology brings opportunities to industrial design as well as brings a series of challenges. When we seize the opportunity, we must also face the challenge. Only when we meet the challenge and sum up experience and lessons, we can make steady progress and welcome the arrival of industry 4.0 .

Industrial design service mode adjustment. As mentioned earlier, the emergence of 3D printing technology will inevitably change the traditional manufacturing methods. The cost of mass production and single-volume production is almost the same, large-scale production advantages are bound to gradually disappear. The future production patterns will also shift from intensive to decentralize. Therefore, the service model of industrial design must be changed as soon as possible so as to meet the requirements of the new situation [12]. So all major manufacturing enterprises should seize the opportunity to change the mode of production and service of industrial design so as to adapt to the change of the present mode of production as soon as possible.

Redefinition and protection of intellectual property. Products once digital data files can be used to describe, it will become more easily copied and imitation, and cottage products will be more and more. The advent of 3D printing technology makes it easier for generic users to launch identical products on the market, so it is important to study further how to protect intellectual property rights.

More worth considering is how to maintain the order of future society if we can copy and print anything using a 3D printer, such as ATM cards, keys, firearms and so on[13]. Therefore, the design of new products related to intellectual property rights should be redefined and protected, the relevant departments should promptly develop or update the law of intellectual property protection.

The rapid shortage of professionals. Of course, the rapid development of $3 \mathrm{D}$ printing technology cannot be separated from the support of talented people. With the advent of the era of 
3D printing, more and more professional and technical personnel will be required in all aspects of industrial design. With the advent of the era of 3D printing, industrial design professionals in all fields will need more and more professionals. As advanced technology, 3D printing will lead to the current product design and manufacturing model of change, which inevitably cannot do without strong technical and administrative skills of high-quality applied talents.

At the same time, in the process of 3D printing, still will involve many professional techniques, such as 3D design, three-dimensional modeling, and post-processing of the product after printing is completed. This requires staff to master a variety of basic skills, such as polishing techniques, firing, cutting and assembling mastery of skills is particularly important [14]. Therefore, colleges and universities need to improve the intensity of personnel training, and more for the community to train more high-quality, high-skilled professional talents. Firmly grasp the school - enterprises co-cultivate the teaching model, schools provide personnel, enterprises provide equipment and funds to enable students to master higher, stronger and more professional skills.

\section{Conclusions}

Today's society will be the era of great changes in science and technology, and continue to make breakthroughs, it is also an era in which advanced manufacturing technologies rapidly developing and being widely used. 3D printing technology will affect almost every aspect of the future industrial design, industrial design is mainly based on innovative design, due to the introduction of three-dimensional printing technology, making the field has a booming prospects. Through the research of 3D printing in the field of industrial design, 3D printing technology has brought good opportunities for industrial design. Industrial designers can completely break the traditional concept of manufacturing process, break the traditional design concept, design more fresh and personalized products are widely used in all areas of industrial design. At present, there are many manufacturing industry using 3D printing technology for product production, not only improve the production efficiency of enterprises, but also received a huge profit At the same time, designers will make more good ideas into reality, from many aspects to meet the needs of consumers and benefit for mankind.

\section{References}

[1] X.L. Li, X.J. Ma, W.M. Zhou, Q. Chen and P. Li: Automation Instrumentation, Vol. 35 (2014) No.01, p.1.

[2] D. Liu: Research in Higher Education of Engineering, (2012) No.01, p.34.

[3] N. Zhang and F. Li: Journal of Machine Design, Vol. 30 (2013) No.07, p.97.

[4] Y.T. Zhao: Machine China, (2015) No.03, p.40.

[5] T. Zheng: Education and Teaching Forum, (2016) No.15, p.225.

[6] N. Qi, X. Zhang, T.M. Jia and X.J. Li: Industrial Design Research, Vol. 11 (2016) No.04, p.67.

[7] Y.S. Shi, L.C. Zhang, Y. Bai and Z.Y. Zhao: Science China Press, Vol. 45 (2015) No.2, p.197.

[8] K. Wang, X.T. Huang and H. Yuan: Machine Design and Manufacturing Engineering, Vol. 44 (2015) No.10, p.1.

[9] J. Yang: Modern Manufacturing Technology and Equipment, (2017) No.01, p.140.

[10] D.J. Zhou: Electro-Mechanical Engineering, Vol. 33 (2017) No.02, p.13.

[11]X. Liu and J.F. Huang: Chinese Journal of Construction Machinery, Vol. 13 (2015) No.01, p.82.

[12] C. Ren, J. Huang and C.L. Guan: Mechanical Research \& Application, Vol. 27 (2014) No.1, p.62.

[13]L.X. Zhou, X.K. Chen and X. Wu: Technology Innovation and Application, Vol. 28 (2017) No.28, P.28.

[14]Z.Y. Deng, J. Zhang, Y.B. Liu and J.R. Xiao: China Machine Engineering, Vol. 16 (2015) No.06, p.766. 